\title{
160-Gb/s CWDM Capacity Upgrade Using 2.5-Gb/s Rated Uncooled Directly Modulated Lasers
}

\author{
Hans J. Thiele, Member, IEEE, Peter J. Winzer, Associate Member, IEEE, Jeffrey H. Sinsky, Member, IEEE, \\ Larry W. Stulz, Lynn E. Nelson, Member, IEEE, and Franz Fidler
}

\begin{abstract}
Uncooled 2.5-Gb/s directly modulated lasers are used to demonstrate a coarse wavelength-division-multiplexed (CWDM) transmission capacity of $160 \mathrm{~Gb} / \mathrm{s}$. All $16 \mathrm{CWDM}$ channels, modulated at $10 \mathrm{~Gb} / \mathrm{s}$, are simultaneously transmitted over $40 \mathrm{~km}$ of uncompensated low-water-peak nonzero dispersion fiber. Operation with bit-error ratio $B E R<1 E-9$ is demonstrated for all 16 channels from room temperature to at least $65^{\circ} \mathrm{C}$.
\end{abstract}

Index Terms-Coarse wavelength-division multiplexing (CWDM), metro transmission, uncooled lasers.

\section{INTRODUCTION}

$\mathbf{C}$ OARSE wavelength-division multiplexing (CWDM) provides a cost-effective system architecture for multichannel transmission in fiber-exhaust metro access networks such as metro-feeders and central office interconnects. In these unamplified short-reach systems, up to 18 low-cost uncooled directly modulated lasers (DMLs) are spaced on a 20-nm wavelength grid between 1270 and $1610 \mathrm{~nm}$. Transmission over the entire 340-nm-wide low-loss window is enabled by low water-peak single-mode fiber, which eliminates the typical $\mathrm{OH}^{-}$absorption peak near $1385 \mathrm{~nm}$.

Full-band CWDM transmission between 1310 and $1610 \mathrm{~nm}$ using 16 DMLs at $2.5-\mathrm{Gb} / \mathrm{s}$ line rate has already been demonstrated over distances up to $75 \mathrm{~km}$ [1], with an aggregate system capacity of $40 \mathrm{~Gb} / \mathrm{s}$. Approaches for increased CWDM capacity include migrating to $10-\mathrm{Gb} / \mathrm{s}$ uncooled DMLs, as reported in [2], or setting up hybrid architectures by replacing some CWDM channels with bands of DWDM channels [3]. Another cost-effective solution is the operation of widely available low-speed $(2.5 \mathrm{~Gb} / \mathrm{s})$ DMLs at higher bit rates by optimizing the mounting and driving conditions of the lasers. A similar approach has been demonstrated for single lasers up to $40 \mathrm{~Gb} / \mathrm{s}$ [4], but has not yet been investigated in detail for an appreciably large ensemble of nonselected nominally equal CWDM lasers with typical performance variations and over an extended range of temperatures.

In this work, we show simultaneous $10-\mathrm{Gb} / \mathrm{s}$ transmission of all 16 CWDM wavelengths using commercial DMLs rated

Manuscript received April 23, 2004; revised June 18, 2004.

H. J. Thiele was with OFS, Holmdel, NJ 07733 USA. He is now with the Fraunhofer Institute of Telecommunications, Heinrich-Hertz-Institut, 10587 Berlin, Germany (e-mail: thiele@hhi.fhg.de).

P. J. Winzer, J. H. Sinsky, and L. W. Stultz are with Lucent Technologies, Holmdel, NJ 07733 USA (e-mail: winzer@lucent.com).

L. E. Nelson is with OFS, Sommerset, NJ 08873 USA (e-mail: lenelson@ofsoptics.com).

F. Fidler is with the Institute of Communications and Radio-Frequency Engineering, Vienna University of Technology, Vienna, Austria.

Digital Object Identifier 10.1109/LPT.2004.834478

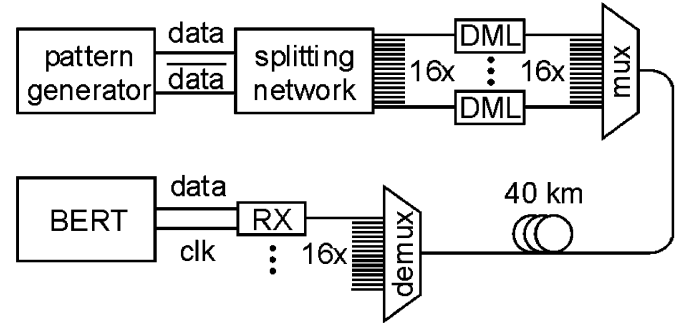

Fig. 1. System setup for $16 \times 10-\mathrm{Gb} / \mathrm{s}$ CWDM transmission upgrade.

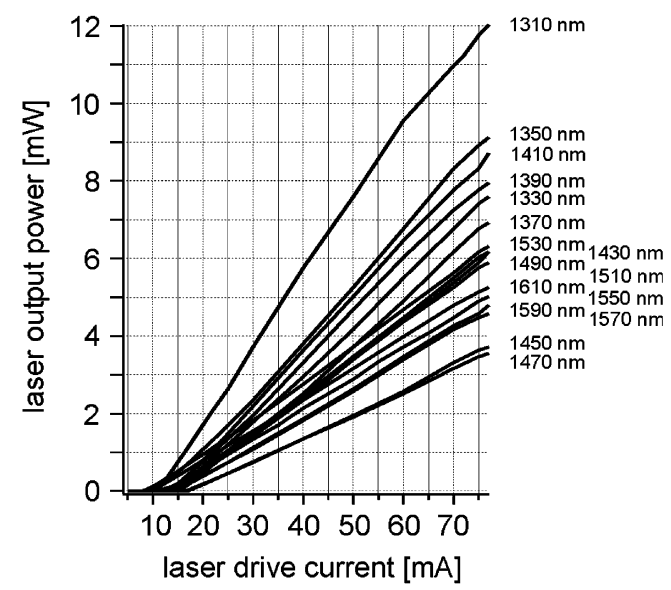

Fig. 2. Output power versus drive current characteristics of all $16 \mathrm{CWDM}$ lasers at room temperature.

for $2.5-\mathrm{Gb} / \mathrm{s}$ operation. We use a prototype nonzero dispersion fiber (NZDF) with low water-peak [5], allowing 40-km uncompensated transmission for all channels, to maintain even at higher bit rate a distance comparable to that achieved for conventional 2.5-Gb/s DML transmission over a standard-dispersion low-water peak fiber (AllWave) link [1]. Furthermore, our temperature tests showed that all channels maintained $10-\mathrm{Gb} / \mathrm{s}$ error-free transmission (bit-error ratio (BER) $<1 E-9$ ) over the $40 \mathrm{~km}$ at operating temperatures up to $65^{\circ} \mathrm{C}$.

\section{EXPERIMENTAL SETUP}

As shown in Fig. 1, we used 16 commercially available uncooled DMLs, rated for $2.5-\mathrm{Gb} / \mathrm{s}$ modulation, at wavelengths from 1310 to $1610 \mathrm{~nm}(\mathrm{CWDM})$. The lasers were simultaneously driven by $9.95-\mathrm{Gb} / \mathrm{s}$ pseudorandom bit sequences of length $2^{31}-1$ via a $2: 16$ electrical splitting network. The DMLs were not preselected and thus exhibit widely varying characteristics in terms of output power versus drive current, as shown in Fig. 2. As a result, laser currents and drive voltages 


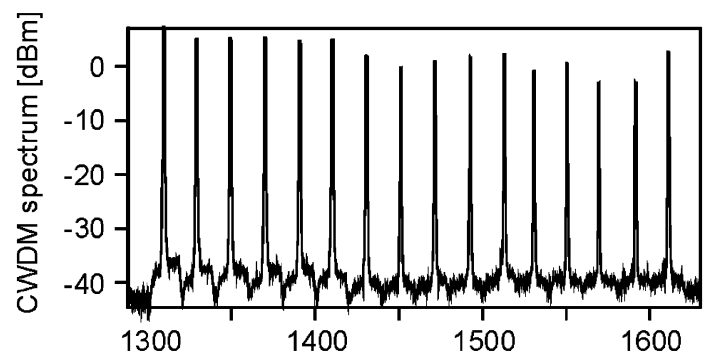

(a)

wavelength [nm]

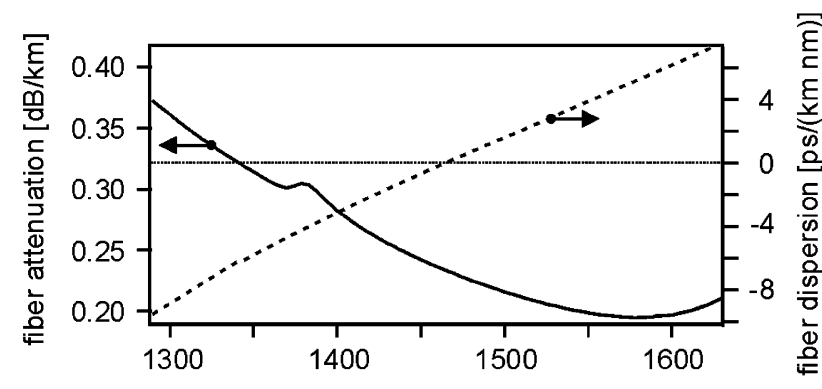

(b)

wavel ength $[\mathrm{nm}]$

Fig. 3. (a) CWDM spectrum at fiber input, (b) fiber attenuation (solid, right scale), and fiber dispersion (dashed, right scale).

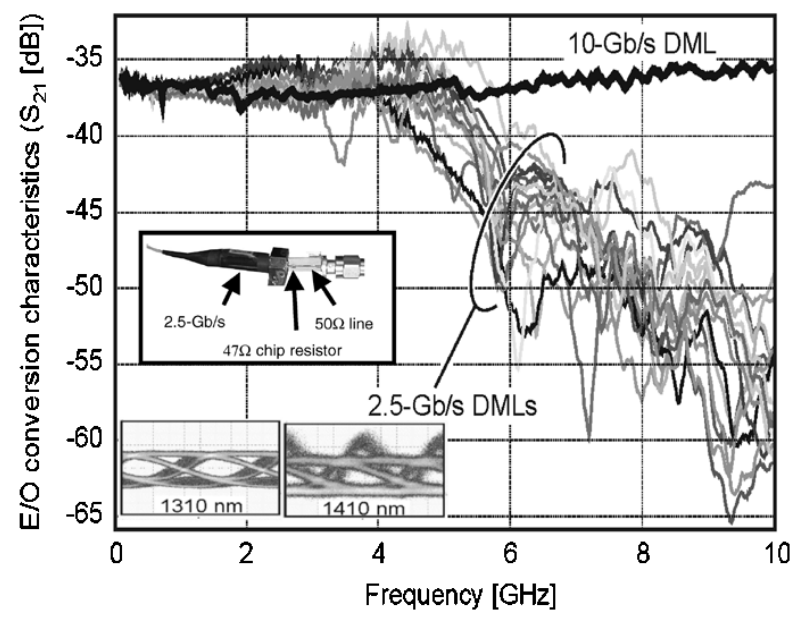

Fig. 4. Small-signal modulation characteristics of all 2.5-Gb/s DMLs, and characteristics of a typical 10-Gb/s DML. Inset: $2.5-\mathrm{Gb} / \mathrm{s}-$ rated DML mounted on mircrostrip line. Below: different back-to-back eye digrams for optimized CWDM 10-Gb/s transmission.

ranged from 30 to $70 \mathrm{~mA}$, and from 1.6 to $3 \mathrm{~V}$, respectively. The 20-nm spaced optical data signals were combined using a thin-film filter-based CWDM multiplexer before propagating over $40 \mathrm{~km}$ of low water-peak NZDF with 1465-nm zero-dispersion wavelength and $0.047-\mathrm{ps} /\left(\mathrm{km} \cdot \mathrm{nm}^{2}\right)$ dispersion slope. The CWDM spectrum at the fiber input, together with the fiber's attenuation and dispersion characteristics, are shown in Fig. 3. A CWDM demultiplexer was used to separate the channels before entering an avalanche-photodiode receiver with a $10-\mathrm{Gb} / \mathrm{s}$ sensitivity of $-25 \mathrm{dBm}$ at $1550 \mathrm{~nm}$ and at a $\mathrm{BER}$ of $\mathrm{BER}=10^{-9}$.

\section{LASER CHARACTERIZATION}

As shown in the inset to Fig. 4, each $2.5-\mathrm{Gb} / \mathrm{s}-$ rated DML in a coaxial package was mounted at the end of a $50-\Omega$ mi-

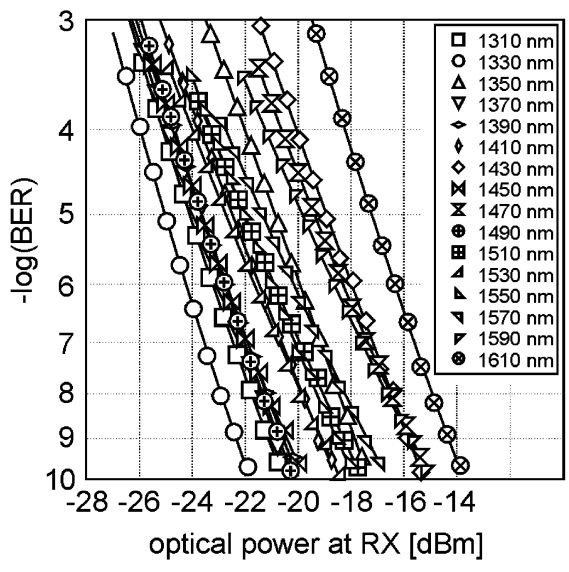

Fig. 5. BER of all 16 channels after simultaneous propagation over $40 \mathrm{~km}$ of fiber.

crostrip line, in series with a $47-\Omega$ surface mount chip resistor. To achieve good performance at microwave frequencies, the resistor is placed as close as possible to the DML package. Such careful laser mounting significantly improved the DMLs' modulation response at low frequencies $(<4 \mathrm{GHz})$ although this can result in increased link penalty due to the lowered extinction ratio. However, the mounting had no impact on the high-frequency behavior, which was mostly determined by the intrinsic properties of the lasers themselves. Fig. 4 shows a comparison of the small-signal modulation characteristics of all 16 DMLs at $25^{\circ} \mathrm{C}$, together with the characteristics of a commercial $10-\mathrm{Gb} / \mathrm{s}-$ rated DML. At frequencies below $4 \mathrm{GHz}$, both the 2.5-Gb/s DMLs and the 10-Gb/s DML exhibit similar performance; however, a fast rolloff at about $4 \mathrm{GHz}$ is consistently found for all 2.5-Gb/s DMLs. Apart from the significant scatter in the lasers' frequency response (cf. Fig. 4), we also noticed that for a similar bias current, some DMLs yield better results when operated for the relatively high bias current at low (3-4 dB) extinction ratios [4], while others prefer to be driven with larger RF amplitudes, with the "0" level close to their lasing thresholds of typically 15-20 mA, resulting in better extinction at the expense of significant amplitude overshoot. The insets to Fig. 4 show the back-to-back eye diagrams for two of the lasers, indicating the two different modes of operation $(10-\mathrm{GHz}$ electrical filter bandwidth).

\section{SYSTEM RESUlTS}

Fig. 5 shows the BER for all 16 channels as a function of the optical power at the receiver after CWDM propagation over $40 \mathrm{~km}$ of NZDF and at $25^{\circ} \mathrm{C}$. Laser bias current and drive voltage as well as the receiver's decision threshold were adjusted for optimum BER. No indications of an error floor were found down to BER $=10^{-10}$, and no sensitivity difference was observed when turning off all neighboring channels, indicating negligible crosstalk. The large scatter in the DMLs' characteristics (Figs. 2 and 4) and chirp behavior [1] is reflected in the $\sim 8 \mathrm{~dB}$ of sensitivity variation among the 16 channels. Fig. 6(a) summarizes the receiver sensitivities $\left(\mathrm{BER}=10^{-9}\right)$ after $40 \mathrm{~km}$ of CWDM-propagation for all channels at $25^{\circ} \mathrm{C}$ (solid squares). The solid triangles show the available power 

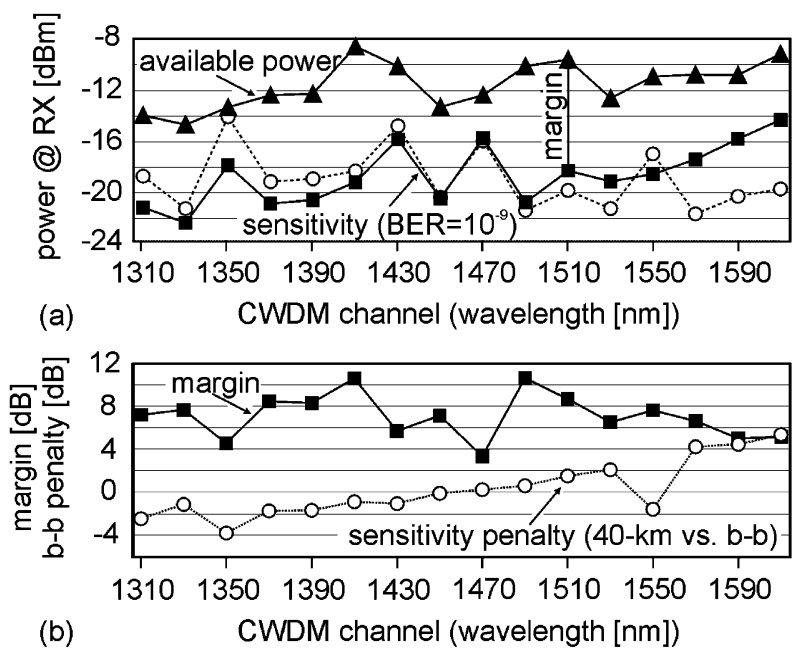

Fig. 6. (a) Receiver sensitivity for all CWDM channels ( $\mathbf{\square})$, and available receiver $(\mathrm{O})$. (b) Power margin after $40-\mathrm{km}$ fiber propagation (a) and sensitivity penalty with respect to the back-to-back case $(\bigcirc)$.

at the receiver for each received channel. The difference between the markers indicates a substantial amount of available power margin, e.g., $10 \mathrm{~dB}$ at $1490 \mathrm{~nm}$; the values for system margin are represented in Fig. 6(b) by solid squares. The open circles in Fig. 6(a) and (b) denote the back-to-back sensitivities and the propagation-induced sensitivity penalties, respectively, at $\mathrm{BER}=10^{-9}$, obtained using the same laser driving conditions as in the 40-km case although these conditions are not optimized for back-to-back operation. The negative penalties below $1450 \mathrm{~nm}$ are due to the interaction of positive laser chirp and the negative dispersion of the fiber at those wavelengths.

When speaking about uncooled lasers, it is imperative to demonstrate operation not only at $25{ }^{\circ} \mathrm{C}$, but also at elevated temperatures, where DML characteristics tend to degrade rapidly [6]. Fig. 7 shows, for all CWDM channels, the maximum laser case temperature that still allowed detection with BER $=10^{-9}$ after $40 \mathrm{~km}$ of CWDM-transmission. With the exception of a single device (laser at $1470 \mathrm{~nm}$ ), a temperature of $75^{\circ} \mathrm{C}$ is well supported, and selected devices reach operation temperatures beyond $90{ }^{\circ} \mathrm{C}$ at $10 \mathrm{~Gb} / \mathrm{s}$.

\section{CONCLUSION}

We have demonstrated a novel CWDM transmission upgrade with an aggregate capacity of $160 \mathrm{~Gb} / \mathrm{s}(16 \times 10 \mathrm{~Gb} / \mathrm{s})$ using uncooled, DMLs rated only for $2.5-\mathrm{Gb} / \mathrm{s}$ operation. Without replacing the lasers, and by simple optimization of mounting and
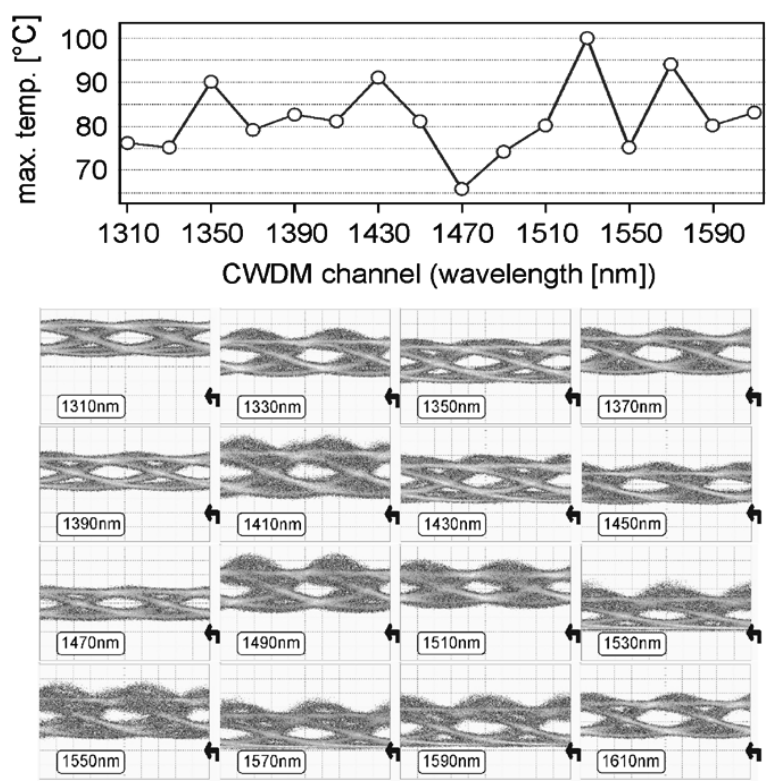

Fig. 7. Top: Maximum achievable laser case temperature allowing BER $=$ $10^{-9}$ after $40-\mathrm{km}$ fiber propagation. Below: Back-to-back eye diagrams for all CWDM channels at maximum temperature for $\mathrm{BER}=10^{-9}$.

driving conditions, we achieved uncompensated $10-\mathrm{Gb} / \mathrm{s}$ transmission of all channels over distances typical for CWDM transmission. For temperatures of at least $65^{\circ} \mathrm{C}$, transmission over $40 \mathrm{~km}$ of fiber was achieved with a BER better than 1E-9 for all 16 lasers.

\section{REFERENCES}

[1] S. K. Das, S. M. Mysore, R. A. Villa, J. J. Thomas, H. J. Thiele, L. Jiao, and L. E. Nelson, " $40 \mathrm{~Gb} / \mathrm{s}(16 \times 2.5-\mathrm{Gb} / \mathrm{s})$ full spectrum coarse WDM transmission over $75 \mathrm{~km}$ low water peak fiber for low-cost metro and cable-TV applications," in NFOEC, Dallas, TX, 2002, pp. 881-887.

[2] I. Sogawa, N. Kaida, K. Iwai, T. Takagi, T. Nakabayashi, and G. Sasaki, "Study on full-spectrum directly modulated CWDM transmission of $10 \mathrm{~Gb} / \mathrm{s}$ per channel over water-peak-suppressed nonzero dispersion shifted fiber," in Eur. Conf. Optical Communication (ECOC 2002), Copenhagen, Denmark, 2002, Paper 8.2.1.

[3] H. J. Thiele, L. E. Nelson, and S. K. Das, "Capacity-enhanced coarse WDM transmission using $10 \mathrm{Gbit} / \mathrm{s}$ sources and DWDM overlay," Electron. Lett., vol. 39, no. 17, pp. 1264-1266, 2003.

[4] K. Sato, S. Kuwahara, Y. Miyamoto, and N. Shimizu, " $40 \mathrm{~Gb} / \mathrm{s}$ direct modulation of distributed feedback laser for very-short-reach optical links," Electron. Lett., vol. 38, no. 15, pp. 816-818, 2002.

[5] K. H. Chang, D. Kalish, and M. Pearsall, "New hydrogen aging loss mechanism in the $1400 \mathrm{~nm}$ window," in Optical Fiber Communication (OFC'99), San Diego, CA, 1999, Postdeadline Paper PD22.

[6] G. Berry et al., " $100^{\circ} \mathrm{C}, 10-\mathrm{Gb} / \mathrm{s}$ directly modulated InGaAsP DFB lasers for uncooled ethernet applications," in Optical Fiber Communication (OFC 2002), 2002, Paper ThF1, pp. 415-416. 